Article

\title{
A Self-Healing Polymer with Fast Elastic Recovery upon Stretching
}

\author{
Pei-Chen Zhao ${ }^{1}$, Wen $\mathrm{Li}^{1}$, Wei Huang ${ }^{1,2, *}$ and Cheng-Hui $\mathrm{Li}^{1, *(1)}$ \\ 1 State Key Laboratory of Coordination Chemistry, School of Chemistry and Chemical Engineering, Nanjing \\ National Laboratory of Microstructures, Collaborative Innovation Center of Advanced Microstructures, \\ Nanjing University, Nanjing 210023, China; zhao_pc84@163.com (P.-C.Z.); \\ 171870585@smail.nju.edu.cn (W.L.) \\ 2 Shenzhen Research Institute of Nanjing University, Shenzhen 518057, China \\ * $\quad$ Correspondence: whuang@nju.edu.cn (W.H.); chli@nju.edu.cn (C.-H.L.); Tel.: +86-025-8966-7389 (C.-H.L.)
}

Academic Editors: Shan-hui Hsu and Martin D. Hager

Received: 25 October 2019; Accepted: 19 January 2020; Published: 30 January 2020

check for updates

\begin{abstract}
The design of polymers that exhibit both good elasticity and self-healing properties is a highly challenging task. In spite of this, the literature reports highly stretchable self-healing polymers, but most of them exhibit slow elastic recovery behavior, i.e., they can only recover to their original length upon relaxation for a long time after stretching. Herein, a self-healing polymer with a fast elastic recovery property is demonstrated. We used 4-[tris(4-formylphenyl)methyl]benzaldehyde (TFPM) as a tetratopic linker to crosslink a poly(dimethylsiloxane) backbone, and obtained a self-healing polymer with high stretchability and fast elastic recovery upon stretching. The strain at break of the as-prepared polymer is observed at about $1400 \%$. The polymer can immediately recover to its original length after being stretched. The damaged sample can be healed at room temperature with a healing efficiency up to $93 \%$ within $1 \mathrm{~h}$. Such a polymer can be used for various applications, such as functioning as substrates or matrixes in soft actuators, electronic skins, biochips, and biosensors with prolonged lifetimes.
\end{abstract}

Keywords: self-healing; PDMS; imine bond; elasticity; polymer

\section{Introduction}

Inspired by the self-healing phenomenon in natural biomaterials, many self-healing polymers have been synthesized to repair internal or external damage. These polymers can self-heal damage through a certain mechanism and therefore prolong the service time of materials in various applications [1-5]. The initial strategy for constructing self-healing polymers is based on incorporating healing agents which are blended into the polymer matrix [6-9]. However, the repairs in such systems can only be repeated for a limited number of times since the encapsulated agents will be depleted after healing. To overcome this limitation, researchers have designed and synthesized new self-healing polymers with reversible chemical bonds (either reversible covalent bonds or dynamic non-covalent interactions). So far, many reversible covalent bonds, such as Diels-Alder (DA) reactions [10-12], [2 + 2] cycloaddition [13,14], acylhydrazone bonds [15,16], trithiocarbonate units $[17,18]$, disulfide moieties [19-21], diarylbibenzofuranone [22,23], and imine bonds [24,25], or non-covalent interactions, such as hydrogen bonds [26-29], hydrophobic interactions [30], $\pi \ldots \pi$ stacking interactions [31-33], ionic interactions [34,35] and metal-ligand interactions [36-44], have been incorporated into various kinds of polymers as cross-linkages, leading to repeatable self-healing polymers.

Elastic polymers have been used in a myriad of products, from hoses and cables to adhesives and clothing. Endowing elastic polymers with self-healing features is therefore of great economic importance. However, synthetic polymers often face a trade-off problem between elasticity and 
self-healing ability. Typically, elastomers are composed of three-dimensional networks of long polymer chains [45]. The elasticity is derived from the ability of the long chains to reconfigure themselves under an applied tension. When the tension is moved, the strong covalent cross-linking sites ensure that the cross-linked networks can recover to their original configuration. Thus, if the cross-linking bonds in polymers are not strong enough, they will be disassociated easily upon stretching, resulting in a permanent deformation. However, weak dynamic bonds are often presented as cross-linking sites for many autonomously self-healing materials. These cross-linking bonds will break upon damage and reform after healing [26-44]. If the cross-linking bonds are too strong, they generally do not show dynamic exchange behavior, and thus polymers based on these bonds cannot self-heal. Therefore, the design of polymers with both good elasticity and self-healing abilities is highly challenging.

Many strategies have been proposed to resolve this conundrum. Guan and colleagues designed stretchable self-healing materials by using a multiphase strategy, in which the stretchability of the materials is conferred by the hard phase while the autonomous self-healing ability is provided by the soft matrix with the multivalent supramolecular interactions $[46,47]$. Suo and colleagues designed many double-network gels that exhibited both high stretchability and self-healing properties [48-50]. Our group and others also designed a series of highly stretchable polymers by elaborately tuning the thermodynamic and kinetic parameters of coordination complexes [37,38,40,44]. However, most of the reported polymers exhibit slow elastic recovery behavior, i.e., they can only recover to their original length after relaxation for a long time upon stretching.

Recently, we reported a polydimethylsiloxane elastomer (BTA-PDMS-25000) which is crosslinked by tetra-functional biphenyl units via imine bonds [51]. The BTA-PDMS-25000 polymer exhibits an impressive self-healing ability (efficient healing within $60 \mathrm{~s}$ at room temperature) and high stretchability (elongation $>8000 \%$ ). However, this polymer is predominantly viscoelastic with significant energy dissipation characteristics. It is desirable to develop new self-healing polydimethylsiloxane elastomers with faster elastic recovery upon stretching. According to the literature, the geometries of cross-linkers have a pronounced effects on the thermal and mechanical properties of polymers [52-54]. We therefore envisage that if the planar cross-linker in BTA-PDMS-25000 was substituted by a non-planar one, PDMS polymers with different mechanical and self-healing properties would be readily obtained. For this consideration, 4-[tris(4-formylphenyl)methyl]benzaldehyde (TFPM), which is a tetrahedral crosslinking unit and has been frequently used in covalent organic frameworks [55-57], is a good choice.

In this work, we used 4-[tris(4-formylphenyl)methyl]benzaldehyde (TFPM) as a tetratopic linker to crosslink a poly(dimethylsiloxane) backbone, and obtained a highly stretchable self-healing polymer with fast elastic recovery upon stretching. The strain at break of the as-prepared polymer is observed at about $1400 \%$. The polymer can immediately recover to its original length after being stretched. At room temperature, the damaged samples can be restored after healing for $1 \mathrm{~h}$, with a healing efficiency up to $93 \%$. Such polymers can be used for various applications, such as functioning as substrates or matrixes in soft actuators, electronic skins, biochips, and biosensors with prolonged lifetimes.

\section{Results and Discussion}

\subsection{Synthesis and General Characterization}

TFPM-PDMS-25000 was synthesized through a Schiff base condensation reaction between bis(3-aminopropyl)-terminated poly(dimethylsiloxane) $\left(\mathrm{H}_{2} \mathrm{~N}\right.$-PDMS- $\mathrm{NH}_{2}, \mathrm{M}_{\mathrm{n}}=25,000$, denoted as PDMS-25000) and TFPM with a molar ratio of 2:1 (Figure 1a). The polymer, which contains polyaldehyde-based molecules as cross-linking points, was synthesized according to the method described in our previous work [51]. The reaction conditions, such as solvent, reaction time, and temperatures can be found in the Experimental section. 
a)

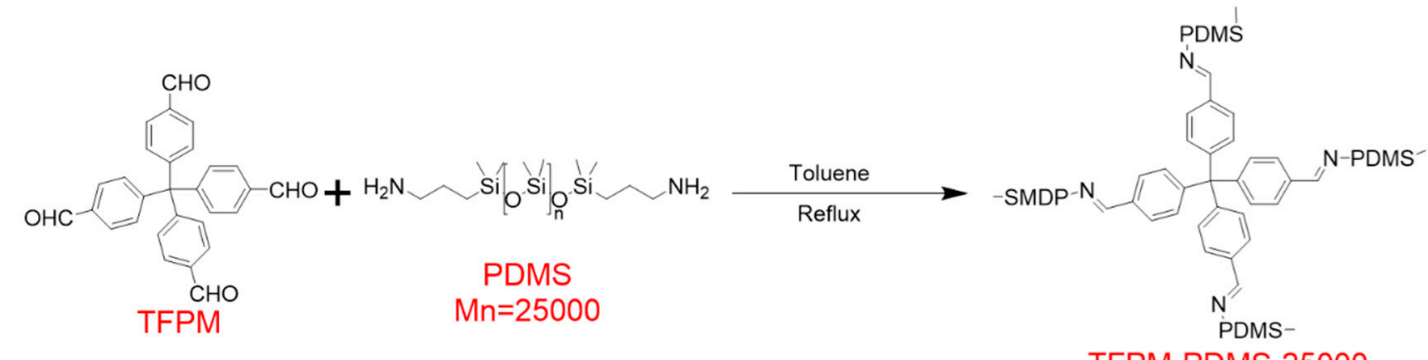

TFPM-PDMS-25000

b)

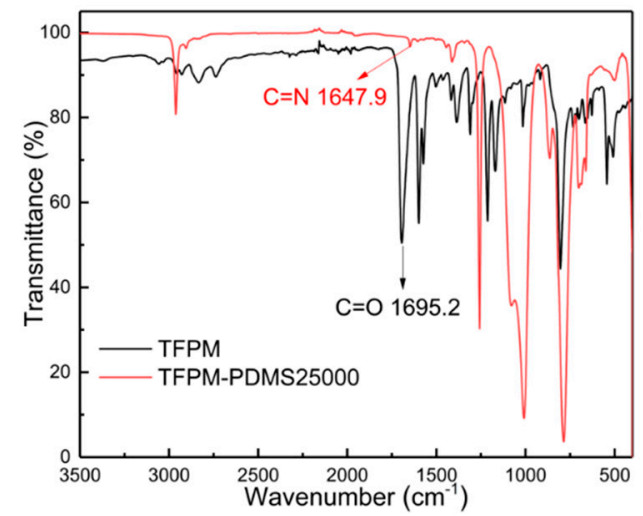

c)

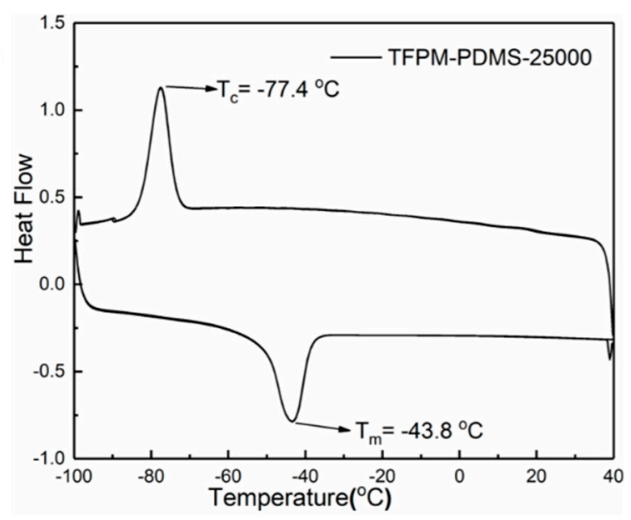

Figure 1. (a) Synthesis route of TFPM-PDMS-25000 polymer. (b) FTIR spectra of TFPM (4-[tris(4-formylphenyl)methyl]benzaldehyde) and TFPM-PDMS-25000. (c) The differential scanning calorimetry (DSC) curve of TFPM-PDMS-25000 polymer.

The TFPM-PDMS-25000 polymer was characterized by FTIR measurements (Figure 1b). A distinctive $\mathrm{C}=\mathrm{O}$ group absorption band can be seen in the FTIR spectrum of TFPM at $1695 \mathrm{~cm}^{-1}$. After reaction of TFPM and PDMS-25000 at $125^{\circ} \mathrm{C}$ for $48 \mathrm{~h}$, the original $\mathrm{C}=\mathrm{O}$ group absorption band finally disappeared and a new absorption band characteristic for a $\mathrm{C}=\mathrm{N}$ stretch appeared at $1647.9 \mathrm{~cm}^{-1}$. These results indicate that the dynamic polyimine network has been formed.

We studied the thermal properties of TFPM-PDMS-25000 with differential scanning calorimetry (DSC) and thermal gravimetric analysis (TGA). As shown in Figure 1c, the exothermal peak at $-77.4^{\circ} \mathrm{C}$ and endothermic peak at $-43.8^{\circ} \mathrm{C}$ in the DSC curves correspond to crystallization and melting, respectively. The glass transition temperature $\left(T_{\mathrm{g}}\right)$ of TFPM-PDMS-25000 polymer must be below $-90^{\circ} \mathrm{C}$ as there is no other exothermal/endothermal signal between the crystallization point and the lowest measurable temperature of our instrument, in dicating that the TFPM-PDMS-25000 polymer is in an elastic state at room temperature $\left(>T_{\mathrm{g}}\right)$ and has high chain mobility. The result from the TGA test demonstrates that TFPM-PDMS-25000 has good thermal stability $\left(T_{\mathrm{d}}=402{ }^{\circ} \mathrm{C}\right.$, corresponding to $10 \%$ weight loss, Figure S1).

\subsection{Rheological Studies}

We used a rotational rheometer to systematically examine the rheological properties of the TFPM-PDMS-25000 polymer. Oscillatory strain sweeps of TFPM-PDMS-25000 showed that the storage modulus $\mathrm{G}^{\prime}(42.5 \mathrm{kPa})$ was about 10-fold higher than the loss modulus $\mathrm{G}^{\prime \prime}(4.4 \mathrm{kPa})$ when the strain was less than $1000 \%$ at $25^{\circ} \mathrm{C}$ (Figure 2a), suggesting that the TFPM-PDMS-25000 polymer is predominantly elastic even at large strains. When the strain was increased $(>1000 \%)$, the polymer network had been partially broken and led to the sample destruction, as indicated by the sudden decrease of $G^{\prime}$ and $G^{\prime \prime}$.

To investigate the dynamic temperature-dependent mechanical properties of the TFPM-PDMS-25000 polymer, we performed dynamic oscillatory temperature sweeps from $0^{\circ} \mathrm{C}$ to $120^{\circ} \mathrm{C}$ at $1 \mathrm{~Hz}$. As presented in Figure 2b, the $G^{\prime}$ of TFPM-PDMS-25000 was almost kept constant at this temperature range. No intersection between $G^{\prime}$ and $G^{\prime \prime}$ was observed in the temperature range from $0{ }^{\circ} \mathrm{C}$ to $120^{\circ} \mathrm{C}$, 
demonstrating the absence of gel-sol transformation. These results suggest that the three-dimensional cross-linking interactions in the TFPM-PDMS-25000 polymer are stable up to $120^{\circ} \mathrm{C}$.

Moreover, we performed frequency sweeps of TFPM-PDMS-25000 polymer films from 0.001 to 628 $\operatorname{rad~s}^{-1}$ at $25^{\circ} \mathrm{C}$. As shown in Figure 2c, the crossover angular frequency $\omega_{\mathrm{c}}$ of TFPM-PDMS-25000 is $0.004 \mathrm{rad} \mathrm{s}^{-1}$. According to the relationship between characteristic relaxation times $\tau_{\mathrm{c}}$ and $\omega_{\mathrm{c}}\left(\tau_{\mathrm{c}}=1 / \omega_{\mathrm{c}}\right)$, the calculated relaxation time $\tau_{\mathrm{c}}$ is $250 \mathrm{~s}$. The relative short relaxation time is an evidence of quick chain mobility and dynamic exchange of imine bonds in the network of the TFPM-PDMS-25000 polymer.

To investigate the recovery after mechanical breakdown, we conducted continuous oscillation-step strain experiments. As shown in Figure 2d, $\mathrm{G}^{\prime}$ decreased when the strain increased from $0.1 \%$ to $1000 \%$, implying partial breakage of the polymer network. When we set back the strain amplitude to $0.1 \%, \mathrm{G}^{\prime}$ partially recovered but $G^{\prime \prime}$ became even smaller, in dicating that there are some broken crosslinking bonds in the polymer that remain unrecovered within this time period.

a)

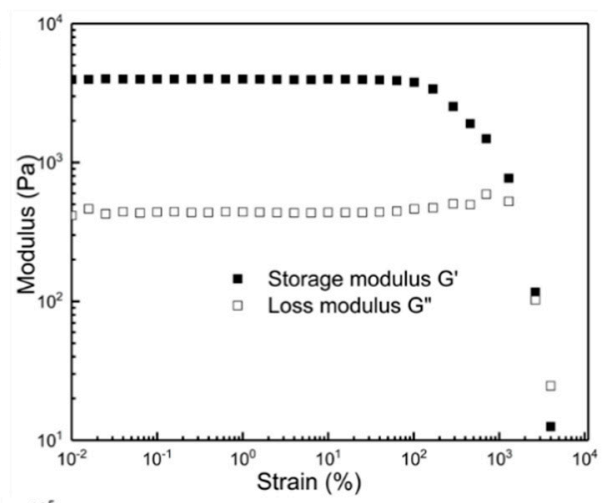

c)

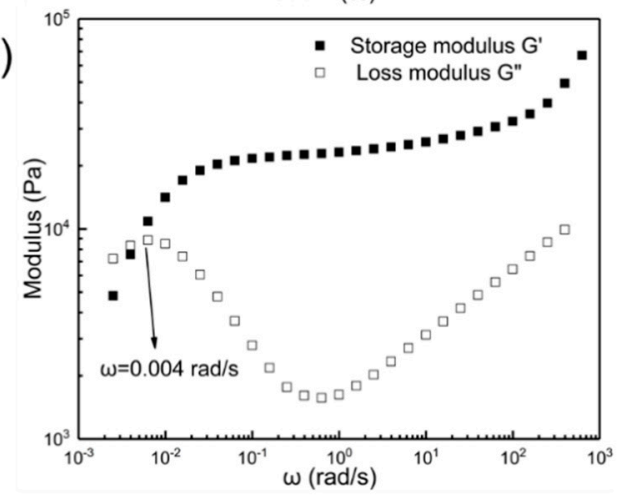

b)

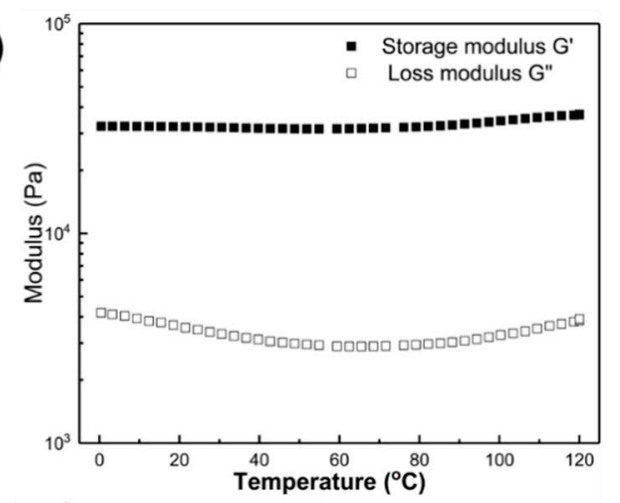

d)

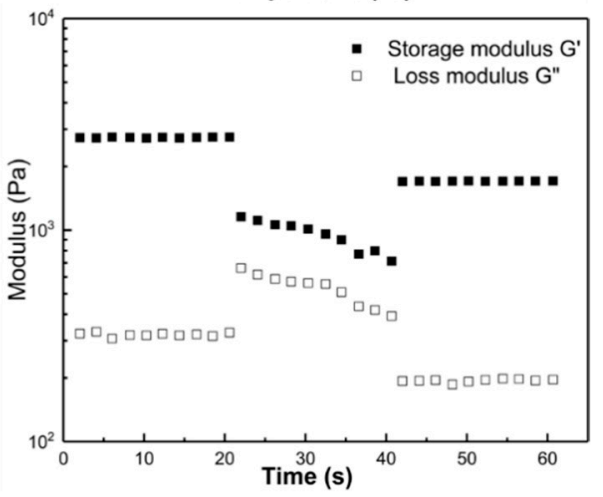

Figure 2. (a) Oscillatory strain sweeps of TFPM-PDMS-25000 at different temperatures. (b) Dynamic oscillatory temperature sweeps of TFPM-PDMS-25000 ranging from $0{ }^{\circ} \mathrm{C}$ to $120^{\circ} \mathrm{C}$ at $1 \mathrm{~Hz}$. (c) Frequency sweeps of TFPM-PDMS-25000 ranging from $0.001 \mathrm{rad} / \mathrm{s}$ to $628 \mathrm{rad} / \mathrm{s}$ with $0.1 \%$ strain amplitude at room temperature. (d) Continuous step strain measurements of TFPM-PDMS-25000 at $25^{\circ} \mathrm{C}$ and $1 \mathrm{~Hz}$, under a small strain amplitude $0.1 \%$ or a large strain amplitude $1000 \%$.

\subsection{Mechanical Property}

The mechanical properties of TFPM-PDMS-25000 polymer were investigated by uniaxial tensile tests under different conditions. As illustrated in Figure 3a, the stretchability of this polymer is in correlation with the stretching rate. When we increased the strain speed from 10 to $100 \mathrm{~mm} \mathrm{~min}^{-1}$, the maximum tensile strength of the TFPM-PDMS-25000 polymer increased from $153.7 \pm 9.3 \mathrm{kPa}$ to $481.1 \pm 8.4 \mathrm{kPa}$, while the ultimate elongation break decreased from $3800 \%$ to $1400 \% \pm 10 \%$. From the low-strain region of the stress-strain curves, the Young's modulus of TFPM-PDMS-25000 was calculated to be $219.7 \pm 8.2 \mathrm{kPa}$. These data show that TFPM-PDMS-25000 has relatively good mechanical strength and high stretchability. 
a)

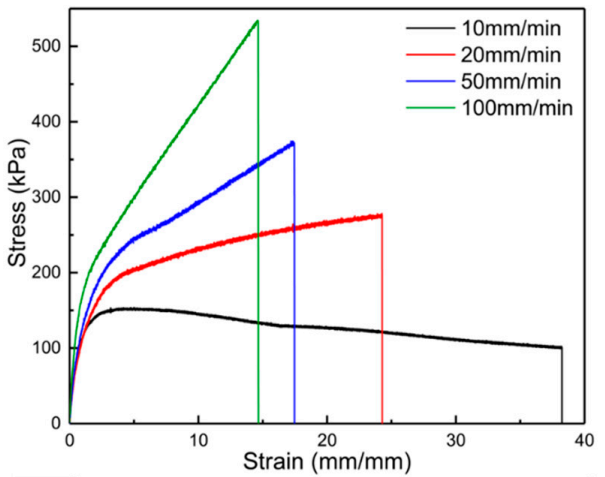

c)

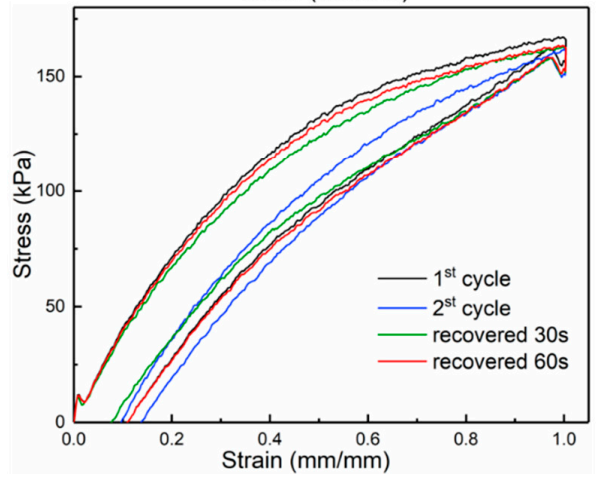

b)

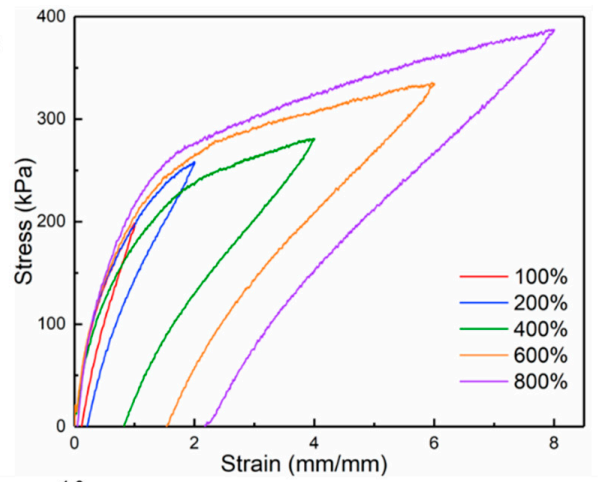

d)

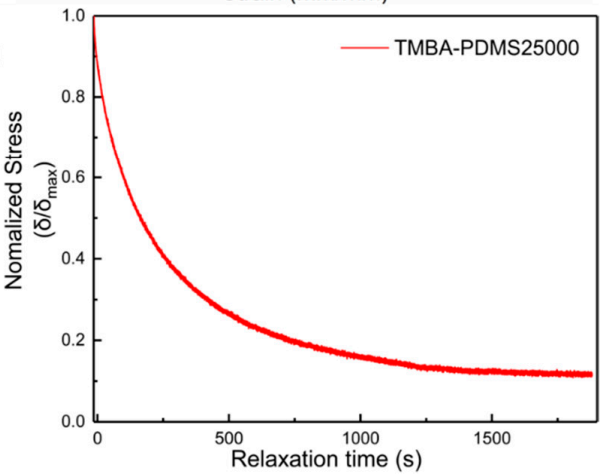

Figure 3. (a) Stress-strain curves of the TFPM-PDMS-25000 samples under different stretch speeds ranging from 10 to $100 \mathrm{~mm} \mathrm{~min}^{-1}$ at $25^{\circ} \mathrm{C}$. (b) Cyclic stress-strain tests of TFPM-PDMS-25000 with different strains at room temperature. Strain rate $=100 \mathrm{~mm} \mathrm{~min}^{-1}$. (c) Cyclic stress-strain tests of TFPM-PDMS-25000 with different relaxation times at room temperature. Strain rate $=100 \mathrm{~mm} \mathrm{~min}^{-1}$. (d) Stress relaxation curves of TFPM-PDMS-25000 that was primarily stretched to 100\% strain and then allowed to relax for $1800 \mathrm{~s}$ at $25^{\circ} \mathrm{C}$.

Next, we performed cyclic stress-strain tests of TFPM-PDMS-25000 under different strains. The loading-unloading curves at 100\%, 200\%, 400\%, 600\%, and 800\% strain, respectively (Figure 3b), show insignificant hysteresis as compared to other highly stretchable self-healing polymers [37,38,41,42], in dicating that TFPM-PDMS-25000 has good elastic recovery. The energy-absorbing efficiencies $(\omega)$ are $23.4 \%$ to $49.7 \%$, from $100 \%$ strain to $800 \%$ strain (Table S2), according to the calculation from the integrated area of loading strain-stress curves W1 and unloading strain-stress curves W2. These numbers are quite small among self-healing polymers [37,38,41,42], in dicating insufficient energy dissipation during stretching. Compared with the original cycle, a distinct hysteresis loop was observed in the second stretch. However, no significant hysteresis was observed in the subsequent three cycles (Figure S2). Moreover, as shown in Figure 3c, if the same sample was allowed to rest for only $1 \mathrm{~min}$ and then tested again, an almost full self-recovery of its original dissipated energy can be observed. When the sample was stretched by hand to about $500 \%$ elongation and then released, it recovered as quickly as a rubber (see Video S1 in the Supporting Information). When the sample was compressed, similar fast recovery behavior was observed (Figures S3 and S4, Video S2).

Figure $3 \mathrm{~d}$ depicts the stress relaxation curves of TFPM-PDMS-25000 film at $25^{\circ} \mathrm{C}$. It can be seen that the normalized stress of TFPM-PDMS-25000 decreased slowly. It takes over $1800 \mathrm{~s}$ for the polymer to release $90 \%$ of the internal stress (from 1 to 0.1 ), much longer than the previously reported stretchable self-healing polymers [51]. This observation further demonstrates that the TFPM-PDMS-25000 film has an excellent elastic recovery.

\subsection{Self-Healing Properties}

The TFPM-PDMS-25000 elastomer also exhibits impressive self-healing properties under ambient conditions $\left(25^{\circ} \mathrm{C}, 60 \pm 5 \%\right.$ Relative Humidity) due to the rupture and reformation of dynamic imine 
bonds. A TFPM-PDMS-25000 polymer film (thickness $\approx 1.5 \mathrm{~mm}$ ) was separated into two pieces using a razor blade and then the pieces were put in contact with each other. We used an optical microscope to record the cutting and healing procedures. As shown in Figure $4 \mathrm{a}$, after healing for $1 \mathrm{~h}$ at ambient temperature $\left(25^{\circ} \mathrm{C}\right)$, the notch on the TFPM-PDMS-25000 film totally disappeared.

a)

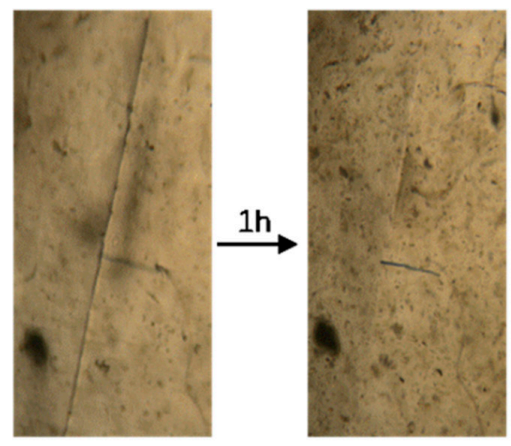

c)

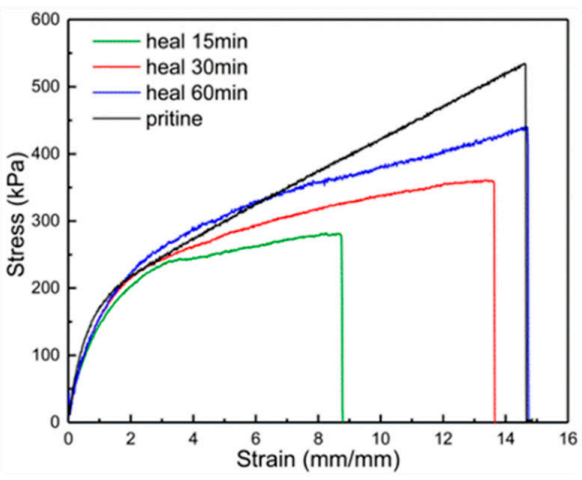

e)
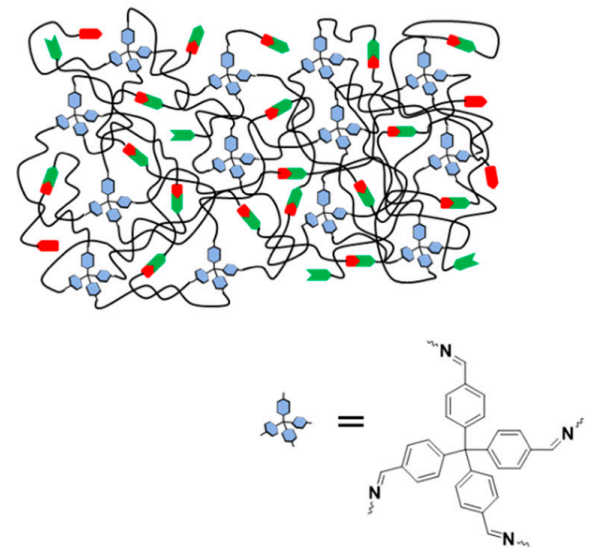

b)
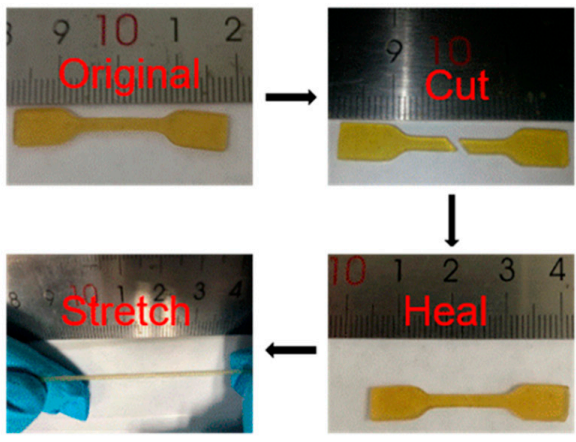

d)
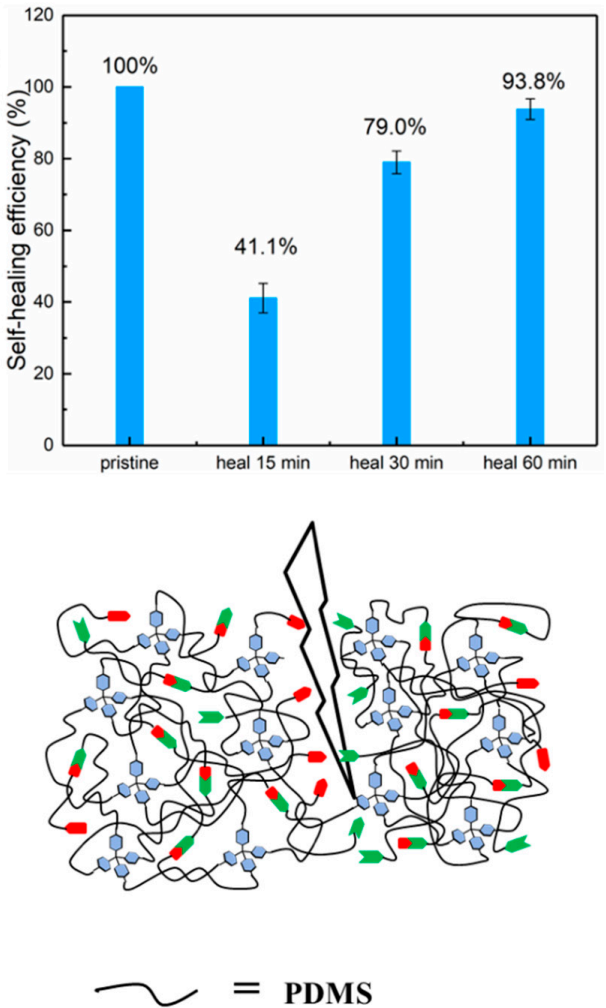

Figure 4. (a) Photographs illustrating the macroscopic cutting-healing-stretching procedure of TFPM-PDMS-25000 films at $25{ }^{\circ} \mathrm{C}$. (b) Photographs illustrating the macroscopic cutting-healing-stretching procedure of TFPM-PDMS-25000 films at $25^{\circ} \mathrm{C}$. (c) Uniaxial tensile tests and (d) self-healing efficiencies of TFPM-PDMS-25000 samples for different times at room temperature.

(e) The possible mechanism for self-healing of the TFPM-PDMS-25000 polymer.

The representative stress-strain curves of the TFPM-PDMS-25000 polymer film healing for different times are shown in Figure $4 \mathrm{~b}$. The mechanical self-healing efficiency $(\eta)$ was calculated from the ratio between the toughness of the healed sample and the toughness of the original sample. In detail, the self-healing efficiency of the TFPM-PDMS-25000 film was 41.1\% $\pm 5.4 \%$ after healing for $15 \mathrm{~min}$. It took $1 \mathrm{~h}$ to completely heal the cut of the sample with an elongation of $1450 \%(\eta=93.8 \% \pm 3.3 \%)$ at room temperature (Figure $4 \mathrm{c}, \mathrm{d}$ ). 
The process of self-healing can even happen in $0{ }^{\circ} \mathrm{C}$ with a healing efficiency of $79.0 \% \pm 3.9 \%$ after $2 \mathrm{~h}$ (Figures S5 and S6). Moreover, we can also merge two undamaged polymer films through self-healing ability. As shown in Figure S5, the polymer film was cut into two pieces and then placed in contact with each other via their undamaged surfaces (Figure S7). These results suggest that the imine bonds in the polymer matrix are dynamically exchanging at room temperature (Figure 4e).

\subsection{Mechanism for the Fast Elastic Recovery}

In our recent work, we reported a polydimethylsiloxane elastomer (BTA-PDMS-25000) which is also crosslinked by tetra-functional biphenyl units via imine bonds [51]. The BTA-PDMS-25000 polymer exhibits an impressive self-healing ability (efficient healing within $60 \mathrm{~s}$ at room temperature) and high stretchability (elongation $>8000 \%$ ). However, this polymer is predominantly viscoelastic with significant energy dissipation characteristics. As shown in Video S1 and Figure 5a,b, in contrast to TFPM-PDMS-25000, the shape of BTA-PDMS-25000 cannot be quickly recovered after stretching. The only difference between these two polymers is that the crosslinking unit is planar in BTA-PDMS-25000 but non-planar in TFPM-PDMS-25000. We therefore speculate that the spatial configuration of the crosslinking unit plays a critical role in the mechanical properties.

It is known that elasticity in polymers originated from the reconfiguration of the chains under an applied tension. If there is viscous deformation and/or bond breakage presented during stretching, then the network will need a longer time to return to its original configuration or it cannot recover when the tension is removed. In BTA-PDMS-25000, the PDMS chains are cross-linked by planar aromatic tetra-functional biphenyl units. The crosslinking units tend to stack together through $\pi$ $\ldots \pi$ interactions. The dynamic $\pi \ldots \pi$ interactions will be broken and re-formed during stretching, leading to sliding of the polymer chains which cause permanent deformation (Figure 5c). In contrast, for TFPM-PDMS-25000, the polymer forms a random three-dimensional network of interconnected chains due to the tetrahedral spatial configuration of tetraphenylmethane units, making it more difficult to flow between polymer chains (Figure $5 \mathrm{~d}$ ). The stretching of the random coil polymer chains in TFPM-PDMS-25000 is reversible, leading to the fast elastic recovery. Moreover, the reduced polymer chain mobility retards the self-healing process. 
a)

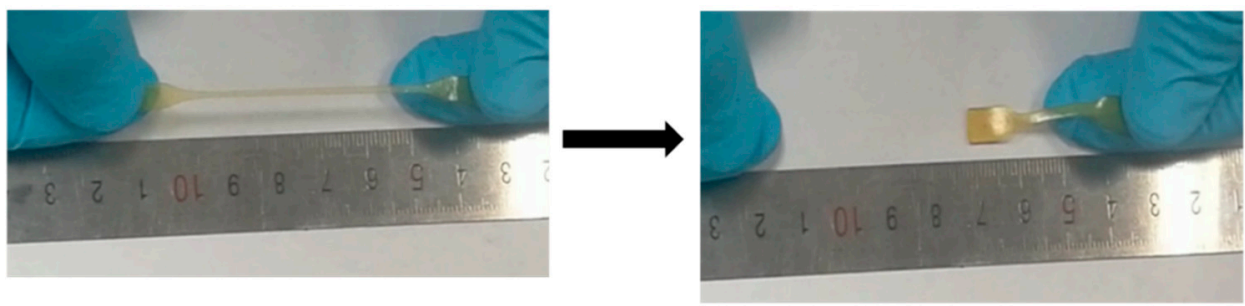

b)

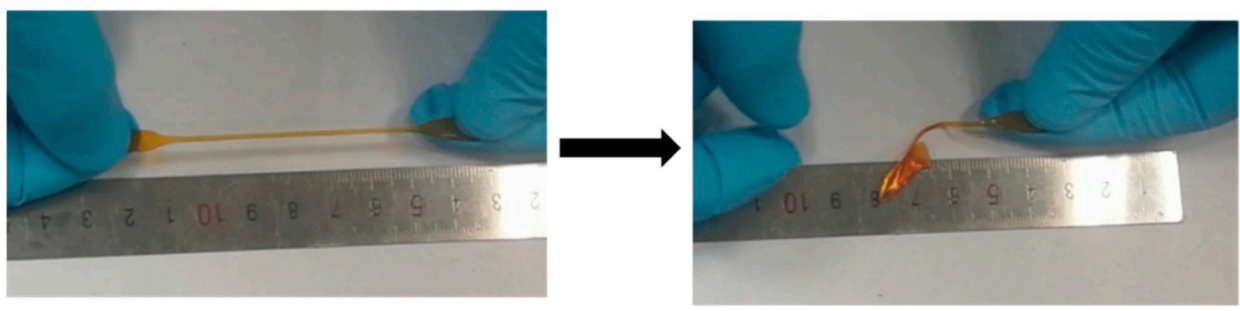

c)
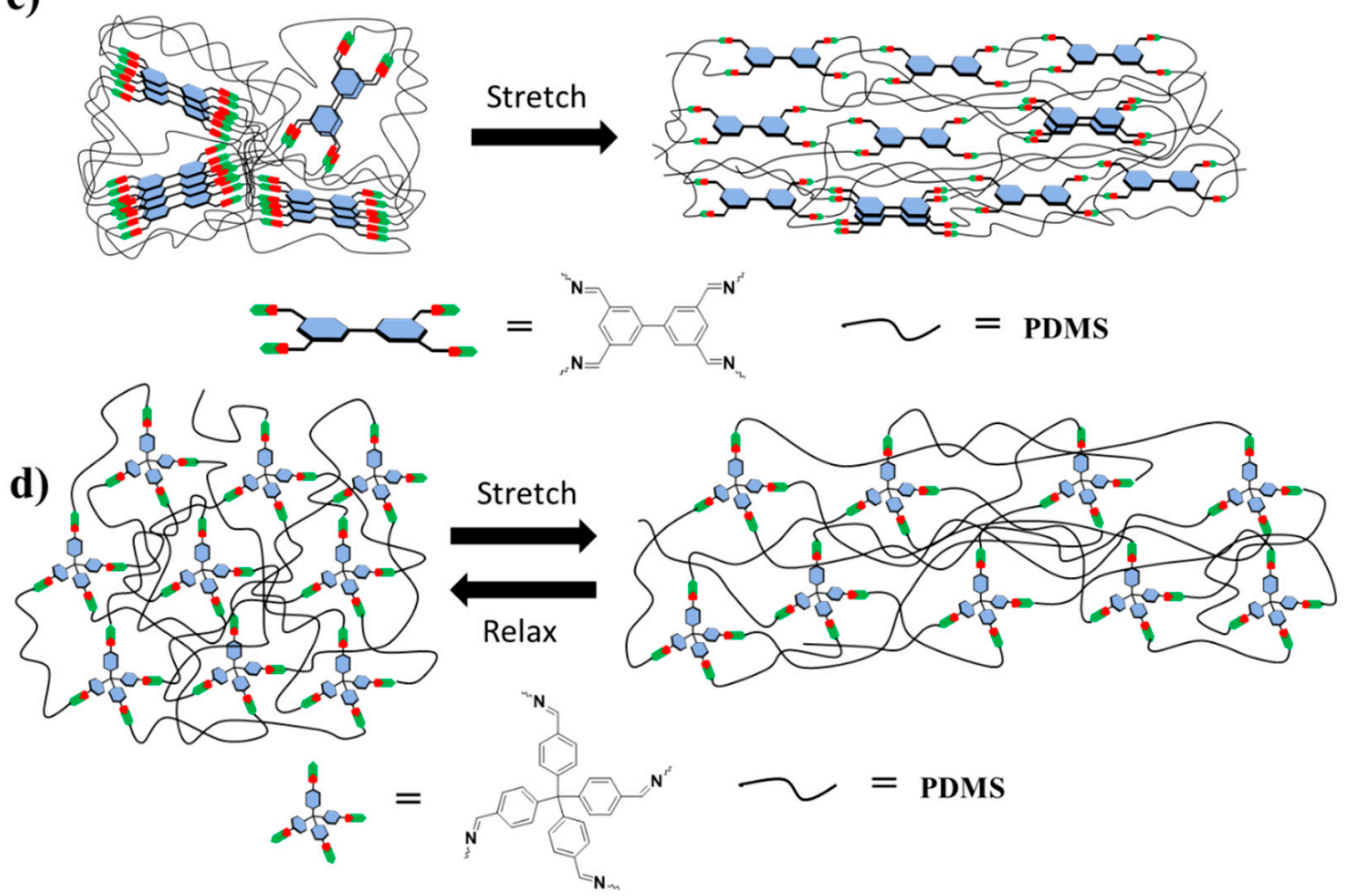

Figure 5. (a) Photographs illustrating the stretching and recovery of BTA-PDMS-25000. (b) Photographs illustrating the stretching and deformation of TFPM-PDMS-25000. (c) The possible mechanism of the stretching and recovery of BTA-PDMS-25000. (d) The possible mechanism of the stretching and recovery of TFPM-PDMS-25000.

\section{Experimental Section}

\subsection{Materials}

Bis(3-aminopropyl) terminated poly(dimethylsiloxane) $\left(\mathrm{H}_{2} \mathrm{~N}-\mathrm{PDMS}-\mathrm{NH}_{2}, \mathrm{M}_{\mathrm{n}}=25,000\right.$, noted as PDMS-25000) was obtained from Gelest. TriphenylMethyl chloride, aniline, isoamyl nitrite, hypophosphorous acid, $n$-Butyllithium $(2.5 \mathrm{~mol} / \mathrm{L}$ in hexane) concentrated sulfuric acid bromine, and the other reagents and solvents were used without further purification after purchasing from Sigma-Aldrich (St. Louis, MO, USA). TFPM was synthesized using the method presented in the literature [55]. 


\subsection{General Measurements}

FTIR spectra were tested with a Bruker (Billerica, MA, USA) Tensor 27 Fourier-transform infrared spectrometer. Thermal gravimetric analysis (TGA) data were performed on a PerkinElmer TA 2100-SDT 2960 (Waltham, MA, USA) under a $\mathrm{N}_{2}$ atmosphere. The temperature range and heating rate for TGA measurement were $30-1000{ }^{\circ} \mathrm{C}$ and $10{ }^{\circ} \mathrm{C} \mathrm{min}^{-1}$, respectively. Differential scanning calorimetry (DSC) experiments were executed on a DSC apparatus of Mettler-Toledo (Zurich, Switzerland) with temperatures ranging from -100 to $40{ }^{\circ} \mathrm{C}$ and heating/cooling speed of $10^{\circ} \mathrm{C} \mathrm{min}{ }^{-1}$ under a nitrogen atmosphere. Temperature and enthalpy calibrations were performed before the experiments using zinc and indium standards. Furthermore, each sample was tested for three cooling-heating runs and the data were procured from the second cooling-heating curves. Optical microscopy images were recorded by Nikon ECLIPSE E100 optical microscope (Tokyo, Japan).

\subsection{Preparation of TFPM-PDMS-25000 Polymer Films}

Under a $\mathrm{N}_{2}$ atmosphere, TPFM (86.5 mg, $\left.0.2 \mathrm{mmol}\right)$ and $\mathrm{H}_{2} \mathrm{~N}-\mathrm{PDMS}-\mathrm{NH}_{2}\left(10.00 \mathrm{~g}, \mathrm{M}_{\mathrm{n}}=25,000\right)$ was added to in redistilled toluene $(200 \mathrm{~mL})$ with constant stirring. The reaction mixture was heated to reflux with an oil bath for $24 \mathrm{~h}$. Then the reaction was cooled down to RT and toluene was partially removed by evaporation under reduced pressure. Then, the remaining part was poured into a polytetrafluoroethylene (PTFE) mold by drying in vacuo (at $90^{\circ} \mathrm{C}, 24 \mathrm{~h}$ ). The TFPM-PDMS-25000 polymer films were then taken out from the PTFE mold and cut into certain dimensions for further testing.

\subsection{Rheological Test}

The rheological measurements were performed on a TA DHR-2 Rheometer (DHR-2, TA Instruments, New Castle, DE, USA). A $20 \mathrm{~mm}$ parallel plate with circular samples of $20 \mathrm{~mm}$ diameter was used during the tests. The gap distance was set to $1000 \mu \mathrm{m}$. Contact force with the sample was set to $0.20 \pm 0.15 \mathrm{~N}$ and maintained by the auto-compression feature. Oscillatory strain sweeps were conducted at $25^{\circ} \mathrm{C}$ and $1 \mathrm{~Hz}$ with stain ranging from $0.01 \%$ to $1000 \%$. Temperature sweeps were performed from $0{ }^{\circ} \mathrm{C}$ to $100{ }^{\circ} \mathrm{C}$ with a sweeping rate of $5{ }^{\circ} \mathrm{C} \mathrm{min}-1$ and a frequency of $1 \mathrm{~Hz}$. In order to keep the measured torque at a reasonable value when the sample was softened, the strain was automatically modulated at $0.10 \% \pm 0.02 \%$ by the instrument. Frequency sweeps were run from 0.001 to $628 \mathrm{rad} \mathrm{s}^{-1}$ with a constant $0.1 \%$ strain amplitude at $25^{\circ} \mathrm{C}$.

\subsection{Mechanical and Self-Healing Measurements}

Uniaxial tensile experiments were conducted at room temperature and on an Instron 3343 (Boston, MA, USA) instrument equipped with a $500 \mathrm{~N}$ load cell. For all the tests, a sample size of $50 \mathrm{~mm}$ length $\times 5 \mathrm{~mm}$ width $\times 1 \mathrm{~mm}$ height was adopted, and each experiment was carried out three times. For the self-healing tests, two completely separate pieces were obtained by cutting the film. The two pieces were then put together and healed at room temperature. The typical strain-stress curves were obtained by measuring the healed samples in the same procedure as the original samples. The strain rate of self-healing tests is $100 \mathrm{~mm} \mathrm{~min}^{-1}$. Maximal stress strengths, breaking strains, and healing efficiencies $(\eta)$ are presented as the means \pm standard deviation according to the data from at least four trials.

\section{Conclusions}

In summary, we synthesized a new self-healing polymer through one-pot aldimine polycondensation. The as-prepared TFPM-PDMS-25000 polymer shows high stretchablity (elongation $>1400 \%$ ) and fast elastic recovery behavior. This polymer also exhibits excellent self-healing properties and can self-heal within $1 \mathrm{~h}$ at room temperature. Such a polymer can be used to prolong the lifetimes of materials in many fabrications, such as sealants, adhesives, coatings, and substrates or matrixes 
for flexible electronic devices. In addition, our results suggest that optimizing the configuration of crosslinking units of a polymer can lead to a combination of elasticity and self-healing properties in a single polymer, which is helpful for further design of self-healing elastomers.

Supplementary Materials: The following are available online: Figure S1: The TGA curve of TFPM-PDMS-25000, Figure S2: Five successive loading-unloading cycles of the film prepared from TFPM-PDMS-25000, Figure S3: The successive loading-unloading cycles of the samples of TFPM-PDMS-25000 and BTA-PDMS-25000 in compression tests, Figure S4. Cyclic stress-strain tests of TFPM-PDMS-25000 in compression tests with different relaxation times, Figure S5: Stress-strain curves of TFPM-PDMS-25000 films healing for different times at $0{ }^{\circ} \mathrm{C}$, Figure S6: Healing efficiencies of TFPM-PEA-25000 with different healing durations at $0{ }^{\circ} \mathrm{C}$, Figure S7: Photographs illustrating the macroscopic cutting-healing-stretching procedure of TFPM-PDMS-25000 films at $25{ }^{\circ} \mathrm{C}$, Figure S8: The energy-absorbing properties of TFPM-PDMS-25000 polymer at 100\% strain, Table S1: Key mechanical properties of TFPM-PDMS-25000 Film (100 $\mathrm{mm} \mathrm{min}^{-1}$ ), Table S2: The energy-absorbing efficiency $\omega$ of TFPM-PDMS-25000 for different strains at room temperature, Video S1: The fast elastic recovery experiment of TFPM-PDMS-25000, Video S2: The plastic deformation of TFPM-PDMS-25000 after 30 min of compression, Video S3: The stretching and deformation of BAT-PDMS-25000.

Author Contributions: P.-C.Z., W.H. and C.-H.L. conceived and designed the experiments; P.-C.Z., W.L. performed the experiments; P.-C.Z. and C.-H.L. analyzed the data; P.-C.Z., W.H. and C.-H.L. wrote the paper. All authors have read and agreed to the published version of the manuscript.

Funding: This research was funded by the National Natural Science Foundation of China (Grant No. 21631006, 21271099 and 21871133), the Natural Science Foundation of Jiangsu Province (Grant No. BK20151377 and BK20171334), and Science, Technology and Innovation Commission of Shenzhen Municipality (No. JCYJ20180307153251975).

Conflicts of Interest: The authors declare no conflict of interest.

\section{References}

1. Binder, W.H. Self-Healing Polymers: From Principles to Applications; Wiley-VCH Verlag GmbH: Weinheim, Germany, 2013.

2. AbdolahZadeh, M.; van der Zwaag, S.; Garcia, S.J. Self-healing corrosion-protective sol-gel coatings based on extrinsic and intrinsic healing approaches. In Self-Healing Materials; Hager, M.D., van der Zwaag, S., Schubert, U.S., Eds.; Springer International Publishing: Cham, Germany, 2016; pp. 185-218.

3. Hia, I.-L.; Vahedi, V.; Pasbakhsh, P. Self-healing polymer composites: Prospects, challenges, and applications. Polym. Rev. 2016, 56, 225-261. [CrossRef]

4. Syrett, J.A.; Becer, C.R.; Haddleton, D. Self-healing and self-mendable polymers. Polym. Chem. 2010, 1, 978-987. [CrossRef]

5. Yang, Y.; Urban, M.W. Self-healing polymeric materials. Chem. Soc. Rev. 2013, 42, 7446-7467. [CrossRef] [PubMed]

6. Samadzadeh, M.; Boura, S.H.; Peikari, M.; Kasiriha, S.; Ashrafi, A. A review on self-healing coatings based on micro/nanocapsules. Prog. Org. Coat. 2010, 68, 159-164. [CrossRef]

7. Seongpil, A.; Min, W.L.; Alexander, L.Y.; Sam, S.Y. A review on corrosion-protective extrinsic self-healing: Comparison of microcapsule-based systems and those based on core-shell vascular networks. Chem. Eng. J. 2018, 344, 206-220.

8. White, S.R.; Sottos, N.R.; Geubelle, P.H.; Moore, J.S.; Kessler, M.R.; Sriram, S.R.; Brown, E.N.; Viswanathan, S. Autonomic healing of polymer composites. Nature 2001, 409, 749-797. [CrossRef]

9. Toohey, K.S.; Sottos, N.R.; Lewis, J.A.; Moore, J.S.; White, S.R. Self-healing materials with microvascular networks. Nat. Mater. 2007, 6, 581-585. [CrossRef]

10. Yu, F.; Cao, X.; Du, J.; Wang, G.; Chen, X. Multifunctional hydrogel with good structure integrity, self-healing, and tissue-adhesive property formed by combining diels-alder click reaction and acylhydrazone bond. ACS Appl. Mater. Interfaces 2015, 7, 24023-24031. [CrossRef]

11. Turkenburg, D.H.; Fischer, H.R. Diels-alder based, thermo-reversible cross-linked epoxies for use in self-healing composites. Polymer 2015, 79, 187-194. [CrossRef]

12. Tanasi, P.; Santana, M.H.; Carretero-González, J.; Verdejo, R.; López-Manchado, M.A. Thermo-reversible crosslinked natural rubber: A diels-alder route for reuse and self-healing properties in elastomers. Polymer 2019, 175, 15-24. [CrossRef] 
13. Abdallh, M.; He, P.; Hearn, M.T.W.; Simon, G.P.; Saito, K. Light-switchable self-healing dynamic linear polymers: Reversible cycloaddition reactions of thymine-containing units. ChemPlusChem 2019, 84, 333-337. [CrossRef] [PubMed]

14. Kim, S.; Kim, B.-H.; Oh, M.; Park, D.H.; Lee, S. Repeatable crack self-healing by photochemical [2 + 2] cycloaddition of TCE-co-DCE monomers enclosed in homopolymer microcapsules. Polymers 2019, 11, 104. [CrossRef] [PubMed]

15. Deng, G.; Tang, C.; Li, F.; Jiang, H.; Chen, Y. Covalent crosslinked polymer gels with reversible sol-gel transition and self-healing properties. Macromolecules 2010, 43, 1191-1194. [CrossRef]

16. Wang, P.; Deng, G.; Zhou, L.; Li, Z.; Chen, Y. Ultrastretchable, self-healable hydrogels based on dynamic covalent bonding and triblock copolymer micellization. ACS Macro Lett. 2017, 6, 881-886. [CrossRef]

17. Dong, P.; Cui, K.; Xu, F.; Jiang, T.; Ma, Z. Synthesis of new ionic crosslinked polymer hydrogel combining polystyrene and poly (4-vinyl pyridine) and its self-healing through a reshuffling reaction of the trithiocarbonate moiety under irradiation of ultraviolet light. Polym. Int. 2018, 67, 868-873. [CrossRef]

18. Yu, L.-X.; Zhuo, D.; Ran, R. Repeatable self-healing of gels based on a dynamic covalent trithiocarbonate cross-linker under microwave irradiation. Int. J. Polym. Mater. Polym. Biomater. 2013, 62, 749-754. [CrossRef]

19. Chang, K.; Han, J.; Gu, S.-Y. A transparent, highly stretchable, self-healing polyurethane based on disulfide bonds. Eur. Polym. J. 2019, 112, 822-831. [CrossRef]

20. Wu, X.; Li, J.; Li, G.; Ling, L.; Zhang, G.; Sun, R.; Wong, C.-P. Heat-triggered poly(siloxane-urethane)s based on disulfide bonds for self-healing application. J. Appl. Polym. Sci. 2018, 135, 46532-46539. [CrossRef]

21. Na, S.; Kim, Y.; Lee, C.; Liechti, K.M.; Suk, J. Adhesion and self-healing between monolayer molybdenum disulfide and silicon oxide. Sci. Rep. 2017, 7, 14740. [CrossRef]

22. Imato, K.; Natterodt, J.C.; Sapkota, J.; Goseki, R.; Weder, C.; Takahara, A.; Otsuka, H. Dynamic covalent diarylbibenzofuranone-modified nanocellulose: Mechanochromic behaviour and application in self-healing polymer composites. Polym. Chem. 2017, 8, 2115-2122. [CrossRef]

23. Imato, K.; Nishihara, M.; Kanehara, T.; Amamoto, Y.; Takahara, A.; Otsuka, H. Self-healing of chemical gels cross-linked by diarylbibenzofuranone-based trigger-free dynamic covalent bonds at room temperature. Angew. Chem. Int. Ed. 2012, 51, 1138-1142. [CrossRef] [PubMed]

24. Zhang, B.; Zhang, P.; Zhang, H.; Yan, C.; Zheng, Z.; Wu, B.; Yu, Y. A transparent, highly stretchable, autonomous self-healing poly(dimethylsilox-ane) elastomer. Macromol. Rapid Commun. 2017, 38, 1700110. [CrossRef] [PubMed]

25. Chao, A.; Negulescu, I.; Zhang, D. Dynamic covalent polymer networks based on degenerative imine bond exchange: Tuning the malleability and self-healing properties by solvent. Macromolecules 2016, 49, 6277-6284. [CrossRef]

26. Kim, S.-M.; Jeon, H.; Shin, S.-H.; Park, S.-A.; Jegal, J.; Hwang, S.-Y.; Oh, D.X.; Park, J. Superior toughness and fast self-healing at room temperature engineered by transparent elastomers. Adv. Mater. 2018, 30, 1705145. [CrossRef]

27. Neal, J.A.; Mozhdehi, D.; Guan, Z. Enhancing mechanical performance of a covalent self-healing material by sacrificial noncovalent bonds. J. Am. Chem. Soc. 2015, 137, 4846-4850. [CrossRef]

28. Yan, X.; Liu, Z.; Zhang, Q.; Lopez, J.; Wang, H.; Wu, H.-C.; Niu, S.; Yan, H.; Wang, S.; Lei, T.; et al. Quadruple H-bonding cross-linked supramolecular polymeric materials as substrates for stretchable, antitearing, and self-healable thin film electrodes. J. Am. Chem. Soc. 2018, 140, 5280-5289. [CrossRef]

29. Herbst, F.; Döhler, D.; Michael, P.; Binder, W.H. Self-healing polymers via supramolecular forces. Macromol. Rapid Commun. 2013, 34, 203-220. [CrossRef]

30. Jiang, H.; Duan, L.; Ren, X.; Gao, G. Hydrophobic association hydrogels with excellent mechanical and self-healing properties. Eur. Polym. J. 2019, 112, 660-669. [CrossRef]

31. Burattini, S.; Greenland, B.W.; Merino, D.H.; Weng, W.; Seppala, J.; Colquhoun, H.M.; Hayes, W.; Mackay, M.E.; Hamley, I.W.; Rowan, S.J. A healable supramolecular polymer blend based on aromatic $\pi-\pi$ stacking and hydrogen-bonding Interactions. J. Am. Chem. Soc. 2010, 132, 12051-12058. [CrossRef]

32. Burattini, S.; Greenland, B.W.; Hayes, W.; Mackay, M.E.; Rowan, S.J.; Colquhoun, H.M. A supramolecular polymer based on tweezer-type $\pi-\pi$ stacking interactions: Molecular design for healability and enhanced toughness. Chem. Mater. 2011, 23, 6-8. [CrossRef] 
33. Burattini, S.; Colquhoun, H.M.; Fox, J.D.; Friedmann, D.; Greenland, B.W.; Harris, P.J.F.; Hayes, W.; Mackay, M.E.; Rowan, S.J. A self-repairing, supramolecular polymer system: Healability as a consequence of donor-acceptor $\pi-\pi$ stacking interactions. Chem. Commun. 2009, 319, 6717-6719. [CrossRef] [PubMed]

34. Chen, T.; Kong, W.; Zhang, Z.; Wang, L.; Hu, Y.; Zhu, G.; Chen, R.; Ma, L.; Yan, W.; Wang, Y.; et al. Ionic iquid-immobilized polymer gel electrolyte with self-healing capability, high ionic conductivity and heat resistance for dendrite-free lithium metal batteries. Nano Energy 2018, 54, 17-25. [CrossRef]

35. Peng, Y.; Yang, Y.; Wu, Q.; Wang, S.; Huang, G.; Wu, J. Strong and tough self-healing elastomers enabled by dual reversible networks formed by ionic interactions and dynamic covalent bonds. Polymer 2018, 157, 172-179. [CrossRef]

36. Weng, W.; Beck, J.B.; Jamieson, A.M.; Rowan, S.J. Understanding the mechanism of gelation and stimuli-responsive nature of a class of metallo-supramolecular gels. J. Am. Chem. Soc. 2006, 128, 11663-11672. [CrossRef] [PubMed]

37. Mei, J.-F.; Jia, X.-Y.; Lai, J.-C.; Sun, Y.; Li, C.-H.; Wu, J.-H.; Cao, Y.; You, X.-Z.; Bao, Z. A highly stretchable and autonomous self-healing polymer based on combination of Pt...Pt and $\pi-\pi$ interactions. Macromol. Rapid Commun. 2016, 37, 1667-1675. [CrossRef]

38. Li, C.-H.; Wang, C.; Keplinger, C.; Zuo, J.-L.; Jin, L.; Sun, Y.; Zheng, P.; Cao, Y.; Lissel, F.; Linder, C.; et al. A highly stretchable autonomous self-healing elastomer. Nat. Chem. 2016, 8, 618-624. [CrossRef] [PubMed]

39. Jia, X.-Y.; Mei, J.-F.; Lai, J.-C.; Li, C.-H.; You, X.-Z. A self-healing PDMS polymer with solvatochromic properties. Chem. Commun. 2015, 51, 8928-8930. [CrossRef]

40. Jia, X.-Y.; Mei, J.-F.; Lai, J.-C.; Li, C.-H.; You, X.-Z. A highly stretchable polymer that can be thermally healed at mild temperature. Macromol. Rapid Commun. 2016, 37, 952-956. [CrossRef]

41. Wang, D.-P.; Lai, J.-C.; Lai, H.-Y.; Mo, S.-R.; Zeng, K.-Y.; Li, C.-H.; Zuo, J.-L. Distinct mechanical and self-healing properties in two polydimethylsiloxane coordination polymers with fine-tuned bond strength. Inorg. Chem. 2018, 57, 3232-3242. [CrossRef]

42. Lai, J.-C.; Li, L.; Wang, D.-P.; Zhang, M.-H.; Mo, S.-R.; Wang, X.; Zeng, K.-Y.; Li, C.-H.; Jiang, Q.; You, X.-Z.; et al. A rigid and healable polymer cross-linked by weak but abundant $\mathrm{Zn}$ (II)-carboxylate interactions. Nat. Commun. 2018, 9, 2725. [CrossRef]

43. Mo, S.-R.; Lai, J.-C.; Zeng, K.-Y.; Wang, D.-P.; Li, C.-H.; Zuo, J.-L. New insights into the mechanical and self-healing properties of polymers cross-linked by Fe(III)-2, 6-pyridinedicarboxamide coordination complexes. Polym. Chem. 2019, 10, 362-371. [CrossRef]

44. Lai, J.-C.; Jia, X.-Y.; Wang, D.-P.; Deng, Y.-B.; Zheng, P.; Li, C.-H.; Zuo, J.-L.; Bao, Z. Thermodynamically stable whilst kinetically labile coordination bonds lead to strong and tough self-healing polymers. Nat. Commun. 2019, 10, 1164. [CrossRef] [PubMed]

45. Sadd, M.H. Elasticity Theory: Applications, and Numerics; Elsevier Butterworth Heinemann: New York, NY, USA, 2005; p. 69.

46. Chen, Y.; Kushner, A.M.; Williams, G.A.; Guan, Z. Multiphase design of autonomic self-healing thermoplastic elastomers. Nat. Chem. 2012, 4, 467-472. [CrossRef] [PubMed]

47. Mozhdehi, D.; Ayala, S.; Cromwell, O.R.; Guan, Z. Self-healing multiphase polymers via dynamic metal-ligand interactions. J. Am. Chem. Soc. 2014, 136, 16128-16131. [CrossRef] [PubMed]

48. Yang, H.; Li, C.; Tang, J.; Suo, Z. Strong and degradable adhesion of hydrogels. ACS Appl. Bio Mater. 2019, 25, 1781-1786. [CrossRef]

49. Yang, H.; Li, C.; Yang, M.; Pan, Y.; Yin, Q.; Tang, J.; Qi, H.; Suo, Z. Printing hydrogels and elastomers in arbitrary sequence with strong adhesion. Adv. Funct. Mater. 2019, 29, 1901721. [CrossRef]

50. Zhang, W.; Liu, X.; Wang, J.; Tang, J.; Hu, J.; Lu, T.; Suo, Z. Fatigue of double-network hydrogels. Eng. Fract. Mech. 2018, 187, 74-93. [CrossRef]

51. Wang, D.-P.; Zhao, Z.-H.; Li, C.-H.; Zuo, J.-L. An ultrafast self-healing polydimethylsiloxane elastomer with persistent sealing performance. Mater. Chem. Front. 2019, 3, 1411-1421. [CrossRef]

52. Clarke, S.M.; Hotta, A.; Tajbakhsh, A.R.; Terentjev, E.M. Effect of cross-linker geometry on equilibrium thermal and mechanical properties of nematic elastomers. Phys. Rev. E 2001, 64, 061702. [CrossRef]

53. Xua, J.; Liu, Z.; Erhan, S.Z.; Carriere, C.J. Cross-linkers control the viscoelastic properties of soybean oil-based biomaterials. J. Am. Oil Chem. Soc. 2004, 81, 813-816. [CrossRef] 
54. Tsuchitani, A.; Ashida, H.; Urayama, K. Pronounced effects of cross-linker geometries on the orientation coupling between dangling mesogens and network backbones in side-chain type liquid crystal elastomers. Polymer 2015, 61, 29-35. [CrossRef]

55. Li, Z.; Li, H.; Guan, X.; Tang, J.; Yusran, Y.; Li, Z.; Xue, M.; Fang, Q.; Yan, Y.; Valtchev, V.; et al. Three-dimensional ionic covalent organic frameworks for rapid, reversible, and selective ion exchange. J. Am. Chem. Soc. 2017, 139, 17771-17774. [CrossRef] [PubMed]

56. Guan, X.; Ma, Y.; Li, H.; Yusran, Y.; Xue, M.; Fang, Q.; Yan, Y.; Valtchev, V.; Qiu, S. Fast, ambient temperature and pressure ionothermal synthesis of three-dimensional covalent organic frameworks. J. Am. Chem. Soc. 2018, 140, 4494-4498. [CrossRef] [PubMed]

57. Lu, Q.; Ma, Y.; Li, H.; Guan, X.; Yusran, Y.; Xue, M.; Fang, Q.; Yan, Y.; Qiu, S.; Valtchev, V. Postsynthetic functionalization of three-dimensional covalent organic frameworks for selective extraction of lanthanide ions. Angew. Chem. Int. Ed. 2018, 57, 6042-6048. [CrossRef]

Sample Availability: Samples of the compound TFPM-PDMS-25000 are available from the authors.

(C) 2020 by the authors. Licensee MDPI, Basel, Switzerland. This article is an open access article distributed under the terms and conditions of the Creative Commons Attribution (CC BY) license (http://creativecommons.org/licenses/by/4.0/). 